\title{
Comparison between seismic retrofitting solutions for existing reinforced concrete buildings: a case study
}

\author{
Francesco Porco and Andrea Fiore* \\ DICATECh, \\ Politecnico di Bari, Via Orabona, \\ 4-70126 Bari, Italy \\ Fax: +39-0805963832 \\ E-mail: francesco.porco@poliba.it \\ E-mail: andrea.fiore@poliba.it \\ *Corresponding author
}

\author{
Siro Casolo \\ Dipartimento ABC, \\ Politecnico di Milano, Piazza L. Da Vinci, \\ 32-20133, Milano, Italy \\ E-mail: siro.casolo@polimi.it
}

\begin{abstract}
In assessing the safety of existing buildings, the specific actions dedicated to the knowledge of the structure delineate the parameters of the linear or non-linear analysis aimed at identifying the most appropriate structural intervention. In this context, the present paper collects the seismic analysis of a school building in reinforced concrete, illustrating the different stages concerning the acquisition of geometrical and mechanical data, problems about structural modelling and the features of the seismic retrofitting proposed. In closing, a critical comparison between the results derived from some techniques frequently used to seismically improve existing structures.
\end{abstract}

Keywords: seismic retrofitting; safety assessment; existing buildings; dissipative systems; case study; reinforced concrete; knowledge level; non-destructive tests; NDT; core drilling; pushover analysis.

Reference to this paper should be made as follows: Porco, F., Fiore, A. and Casolo, S. (2014) 'Comparison between seismic retrofitting solutions for existing reinforced concrete buildings: a case study', Int. J. Structural Engineering, Vol. 5, No. 3, pp.242-261.

Biographical notes: Francesco Porco is a Researcher in Structural Engineering and holds a PhD in Computational Mechanics.

Andrea Fiore is a PhD student in Civil Engineering.

Siro Casolo is an Associate Professor of Structural Mechanics. 


\section{Introduction}

Italian school buildings are marked by a very high seismic vulnerability due to age but especially to the lack, until a few years ago of specific laws relating to seismic design (Raffaele et al., 2013). After the destructive events of the last few years (Rossetto and Peiris, 2009; Mezzina et al., 2009), Italy has launched a substantial renovation of the design procedures. The Ministerial Decree of 14/01/2008 [hereinafter NTC, (2008)] is the final results of this renewal and substantially in line with the European requirements (CEN 2005a, 2005b). Concomitantly, the study of the seismic behaviour, the assessment and design of specific measures to strengthen existing structures, represent the most current topics in the structural engineering field. The different approach between past and present becomes evident when it is necessary to evaluate the existing structures designed to withstand only vertical loads. These structures have a number of intrinsic problems because reflect the knowledge dating back to the time of their realisation. The effects due aging of materials, the past seismic events and possible structural changes are only some problems that affect the existing structures. It is therefore clear that a mathematical model of structure is influenced by many factors. This dependence leads to wide uncertainty caused by the need to simplify the problem by only defining few characteristic parameters. The uncertain level increases if we wish to insert the non-structural elements in the numerical modelling. In the last few years, several research studies have been devoted to the appraisal of uncertainty in the analysis of reinforced concrete buildings. Many of them provide procedure that lead to greatly increase the degree of uncertainty (Celarec and Dolsek, 2013; Celarec et al., 2012; Porco et al., 2014). There are also additional difficulties in preserving the numerous buildings that have a historical importance (just think of the several historical towns that characterise the main European countries). In the picture described so far, the results of analysis about existing buildings are affected by the degree of knowledge and the assumptions made in the numerical modelling. This aspect occurs, even more, when there is the need to choose the technique of seismic retrofitting of structure. There are several techniques able to decrease and/or eliminate the deficit to the seismic actions, some of which are particularly innovative. Among these, the dissipative and base-isolation systems are specific techniques that are developing quickly. In recent years, they have been widely discussed by the scientific community (Mazza and Vulcano, 2009; Ponzo et al., 2012; Mazza, et al., 2012).

This paper presents the results relative to the seismic assessment of a school building built in the early ' $80 \mathrm{~s}$. The structure is in a small village in the Province of Cosenza (in Southern Italy). The study describes seismic assessment (by pushover analysis) of the building after a preliminary analysis about safety level compared to vertical actions. The analysis has allowed to detect a significant structural deficit to the seismic actions. Only the seismic retrofitting interventions can eliminate deficits found. In order to highlight the pros and cons of each optimal solution for the building, a comparison between the performances obtained with two different proposed interventions is shown below. 
The first, relating to a structural traditional intervention (increase of the cross section of the columns) while the second concerns the use of dissipative systems of hysteretic type. Some critical remarks follow the results in order to highlight, for both interventions, advantages and disadvantages in achieving the structural performance shown.

The results and some considerations become a guideline for the choice of the optimal solution because the features of the analysed structure are the most common between the Italian school buildings (age, irregularities, number of floors). The analysis about an irregular building having insufficient seismic capacity make the case study particularly significant (although is the only). A seismic retrofitting intervention must be chosen based on the response that the structure must have after the strengthening.

It is therefore important to have examples, results and remarks in order to assess effective advantages with more awareness.

\section{Knowledge of the school building}

Assessing safety levels of an existing building is an operation that mainly dependent on the knowledge level of the structure. A computational model of the building becomes an efficient tool for assessment the real structural performance only if it is built thanks to several and precise information obtained during the knowledge process. This phase is fundamental because existing structures are affected by a degree of uncertainty greater than new ones. Consequently, the current technical rules [NTC (2008) and Ministerial Circular n. 617 (2009)] provide adequate partial safety factor (PSF) (equal to 1.35, 1.2 and 1) in order to modify the material strength and then, the capacity of beams, columns and infill panels, depending on their knowledge level. These are three and, respectively, indicated as LC1: 'limited', LC2 'adequate': LC3: 'accurate'. They take into account the geometrical features, construction details and material properties (see $\S$ C8A.1.B and see C8A.1.B.3 (Ministerial Circular n. 617, 2009).

Following sections describe the operations performed to collect data that have allowed to assume for the case study, a knowledge level equal to LC2 (PSF = 1.2).

\subsection{Geometrical survey and mechanical characterisation of materials}

The reinforced concrete building has four levels (a basement floor, two floors above ground and an attic only accessible for inspection). A stairwell positioned in the middle of building plan connects the levels. The basement develops into two levels and regards only one portion of the building plan. The building foundations are consequently on different height (Figure 1). 
Figure 1 Architectural plan and front view
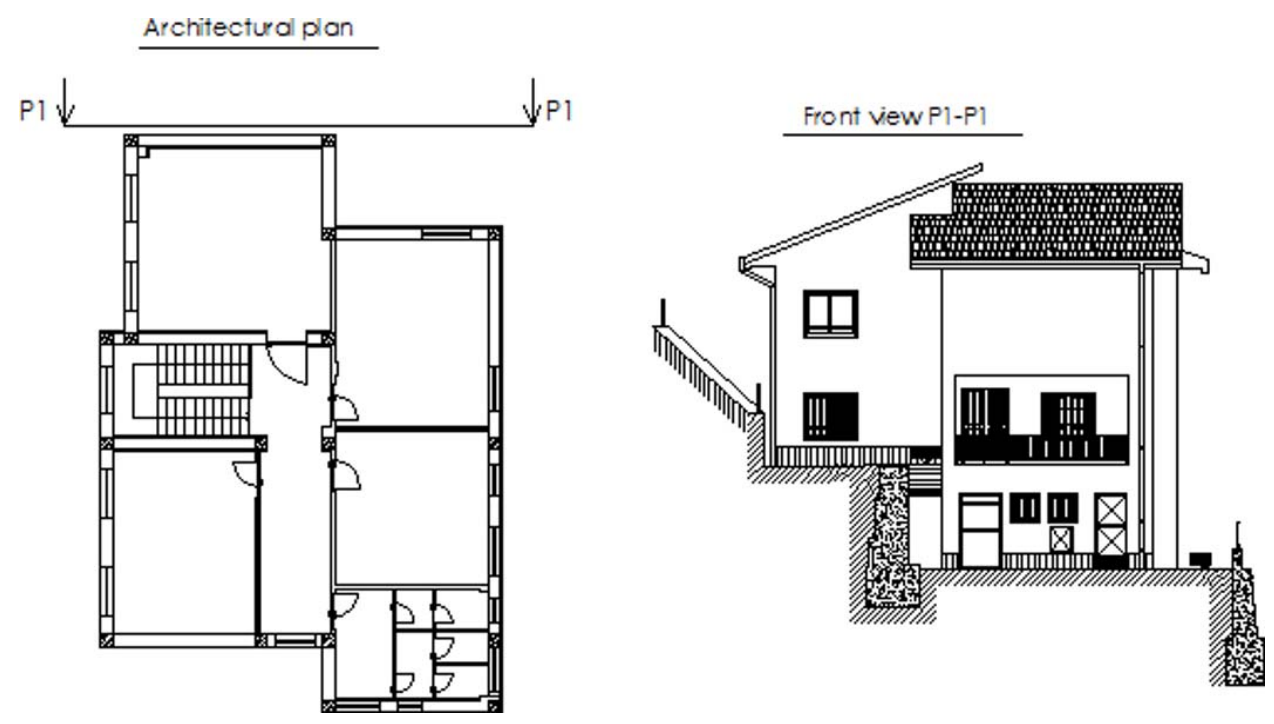

The building plan is rectangular with an area of about $200 \mathrm{~m}^{2}$ and total height of about $13 \mathrm{~m}$ while the interstory one is $3.3 \mathrm{~m}$. The pitched roof has a hipped height equal to $3 \mathrm{~m}$. The columns on the ground floor are all rectangular with dimensions $40 \mathrm{~cm}$ wide and $50 \mathrm{~cm}$ high while on the upper floor have all square cross section $(40 \mathrm{~cm} \times 40 \mathrm{~cm})$. At the first floor, beams have respectively dimensions (width and height) $40 \mathrm{~cm} \times 60 \mathrm{~cm}, 40 \mathrm{~cm}$ $\times 40 \mathrm{~cm} \mathrm{e} 60 \mathrm{~cm} \times 20 \mathrm{~cm}$, while connecting beams between first floor and foundation are $40 \mathrm{~cm}$ wide and $80 \mathrm{~cm}$ high. At the second and third floor, beams are $40 \mathrm{~cm} \times 60 \mathrm{~cm}$, $40 \mathrm{~cm} \times 40 \mathrm{~cm}$ and $50 \mathrm{~cm} \times 20 \mathrm{~cm}$, while the roof beams are $30 \mathrm{~cm} \times 60 \mathrm{~cm}, 40 \mathrm{~cm} \times$ $20 \mathrm{~cm}$ and $30 \mathrm{~cm} \times 20 \mathrm{~cm}$ (these do not have supporting function). The floors have a mixed structure made up of cast-in place concrete, precast lattice joists and hollow tile bricks, for a total height of $20 \mathrm{~cm}$.

Ribbed bars were used as reinforcement and an extensive on site inspection programme was carried out in order to assess the amount of steel in the main structural elements (according to the requirements of a knowledge level 2 [NTC, 2008; Ministerial Circular n. 617, 2009). On the basis of the retrieved data, it was possible to deduce the recurrent reinforcement ratio in the end sections of the beams and columns. Specifically for beams, the longitudinal reinforcement oscillate between $6.28 \mathrm{~cm}^{2}$ and $16.33 \mathrm{~cm}^{2}$ (in correspondence with tension fibres), plus a transversal reinforcement provided by $\phi 6$ stirrups, uniformly spaced every $20 \mathrm{~cm}$. For columns, longitudinal reinforcement on the ground floor is equal to $4 \phi 16$ in the corners and $3 \phi 16$ along the sides, plus $\phi 6$ stirrups, uniformly spaced every $20 \mathrm{~cm}$ as transversal reinforcement.

After completing the complete geometrical survey, a detailed experimental programme has been planned. In order to evaluate the mechanical properties of materials, destructive tests (DT), non-destructive testing (NDT) and laboratory tests on the specimens from the structural elements were carried out. The material tests are specifically: 
- N. 7 extractions of concrete core and execution of laboratory compression test on each sample

- N. 4 samples of reinforcement bars taken on which tension tests were carried out

- N. 6 rebound hammer tests

- N. 16 ultrasonic tests

- N. 18 specific magnetometer survey, both to avoid the interference of the drilling with steel rebars and to verify the distribution of reinforcement bars in structural elements.

Figure 2 Specific plan of experimental surveys - in situ test on the first floor (see online version for colours)

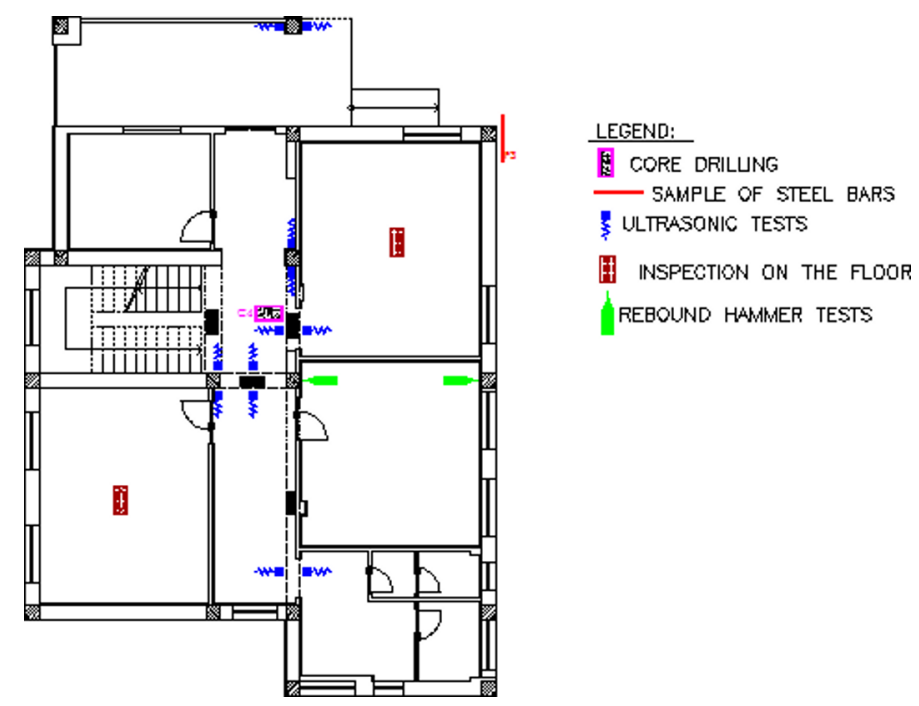

\subsection{Numerical processing of the experimental data}

According to current European and Italian technical rules (NTC, 2008; CEN, 2005b; Ministerial Circular n. 617, 2009), the material mechanical properties must be evaluated by resorting to DT. Thus, the core drillings on the primary structural elements (beams and columns) and the execution of laboratory compressive tests on the obtained samples become the main reference tests. The results obtained by DT methods can be combined with NDT methods, provided that they are calibrated by using the actual results of the destructive laboratory tests. It is widely acknowledged that non-destructive methods cannot completely replace the DT but they can be effectively used to support them. With the aim performing an extensive inspection programme of the structure, which could not be realistically performed with only DT, the non-destructive methods are ideal. In technical literature, there are several studies that propose procedures based on the simultaneous use both methods (DT and NDT) to extend the results obtained by drilled cores (Mikulic et al., 1992; Qasrawi, 2000). 
When discussing about appraisal of the compressive strength of in situ concrete, it should be remembered that the measurements performed on drilled cores are affected by several factors. These characterise the actual strength of the in situ concrete as a 'random variable' (Malhotra, 1974). Some factors derive by drilling operations (shape and diameter of the core, presence of embedded reinforcements, disturbance due to the drilling). Other instead such as for example, the compaction degree (Uva et al., 2013) are external factors and depend by the concrete curing, position of the sample, age of concrete and data scattering (Fiore et al., 2013). Considering the presence of all these disturbing factors and on the other side, the possible implications involved in the judgment about the reliability of the materials, the entire protocol related to the assessment of in situ concrete strength requires great care, both in the carrying out the tests and in the numerical processing of data.

In order to mitigate the effects induced by the disturbing factors, as already mentioned, different formulations have been proposed in the literature for determining the in situ cubic compressive strength $\left(R_{c, s i t u}\right)$ from the cylindrical strength of core samples $\left(f_{\text {core }}\right)$. Among the most recent, the relationship proposed by Masi (2005) is particularly interesting. Even if the notation is different, the conceptual basis is similar to formulation in the Fema-274 (1997).

$$
R_{c, s i t u}=\left(C_{H / D} C_{d i a} C_{a} C_{d} f_{\text {core }}\right) \frac{1}{0.83}
$$

with

$C_{H / D}$ coefficient that corrects the results if the slenderness $\lambda$ is different by 2

$$
C_{H / D}=\frac{2}{\left(1.5+\frac{1}{\lambda}\right)}
$$

$C_{\text {dia }} \quad$ coefficient that take into account the diameter $D$ of core. It is the same used by Fema-274 (1997) and values are 1.06, 1.00 and 0.98 respectively for diameters $50 \mathrm{~mm}, 100 \mathrm{~mm}$ and $150 \mathrm{~mm}$.

$C_{a} \quad$ coefficient that accounts for the presence of steel reinforcements perpendicularly to the core axis. It is equal to 1 if no bar is present, whereas varies from 1.03 for 'small' diameters $(\phi 10)$ to 1.13 for 'large' diameters $(\phi 20)$.

$C_{d} \quad$ coefficient that accounts for the disturbance induced by drilling.

The correction coefficient $C_{d}$ requires a particular attention: even if ACI (2003) suggests a constant value equal to 1.06 , in the technical literature also $C_{d}=1.10$ has been proposed, provided that the extraction is carefully carried out by experienced operators. However, considering that the drilling damage grows higher for poor quality concrete, it appears more suitable to assume $C_{d}=1.20$ for $f_{\text {core }}<20 \mathrm{MPa}$ and $C_{d}=1.10$ for $f_{\text {core }}>$ $20 \mathrm{MPa}$, as suggested in Collepardi (2010). Table 1 shows the classes of concrete obtained by equation (1). Inside, with $f_{c m}$ is the average value of the concrete strength used in tests. It should be noted that for a few data as in this case, the evaluation of statistical dispersion of the sampling is not particularly significant. However, in the case of buildings much more complex where the number of destructive and NDT becomes significant, it is necessary to study the distribution of the sample data and assess the main 
statistical quantities. This approach could provide additional information about the heterogeneity of concrete (Fiore et al., 2013).

Table 1 Numerical processing of DT

\begin{tabular}{|c|c|c|c|}
\hline & $f_{\text {core }}(M p a)$ & $R_{c, \text { sito }}(\mathrm{Mpa})$ & $f_{c m}(M p a)$ \\
\hline Foundation & 11.96 & 14.35 & 14.35 \\
\hline Columns on the ground floor & 15.75 & 18.90 & 19.05 \\
\hline Columns on the 1 st floor & 16.00 & 19.20 & \\
\hline Beams on the 1 st floor & 22.00 & 26.40 & 25.45 \\
\hline Beams on the 3 th floor & 22.28 & 24.51 & \\
\hline Beams on the $2^{\text {nd }}$ floor & 13.30 & 15.96 & 14.76 \\
\hline Columns on the 2 nd floor & 11.31 & 13.57 & \\
\hline
\end{tabular}

The results of NDT confirmed the classes identified by core drillings. In fact, in Figure 3 (where the concrete classes are highlighted with specific colour), the ultrasonic pulse velocities corresponding to the different structural types are very close.

Figure 3 Ultrasonic pulse velocities (see online version for colours)

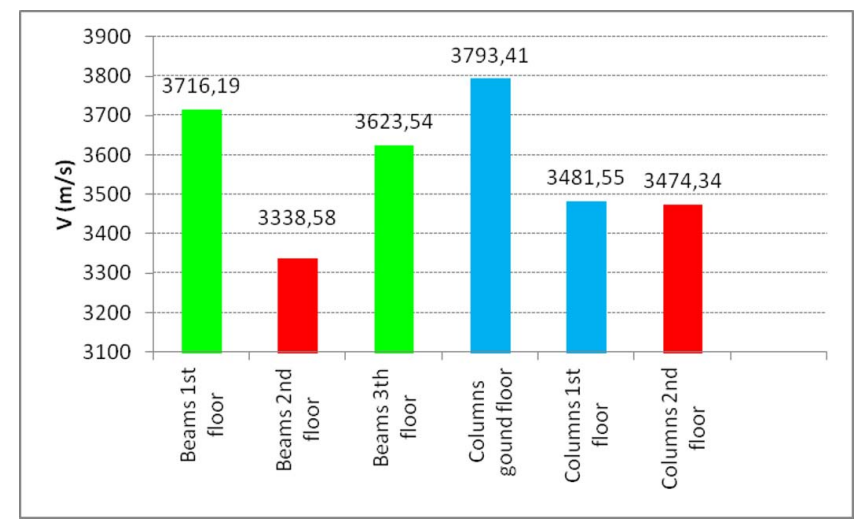

It should be noted that the inaccessibility to the attic floor has made it impossible to carry out investigations on the characteristics of materials related to the columns of the third floor and beams of covering. For these structural elements, the mechanical properties corresponding respectively, to columns and beams of the lower floor were adopted.

Table 2 Concrete and steel strength used for safety assessment

\begin{tabular}{|c|c|c|c|}
\hline & \multirow{2}{*}{ For vertical loads } & \multicolumn{2}{|c|}{ For seismic actions } \\
\hline & & Ductile elements & Brittle elements \\
\hline & $f_{c d}(M p a)$ & $f_{c d}(M p a)$ & $f_{c d}(M p a)$ \\
\hline Foundation & 6.78 & 11.95 & 7.96 \\
\hline Beams on the 1 st floor & 12.02 & 21.20 & 14.13 \\
\hline Beams on the 2 nd floor & 6.97 & 12.30 & 8.20 \\
\hline Beams on the 3rd floor & 12.02 & 21.20 & 14.13 \\
\hline Beams on the covering & 6.97 & 12.30 & 8.20 \\
\hline
\end{tabular}


Table 2 Concrete and steel strength used for safety assessment (continued)

\begin{tabular}{|c|c|c|c|}
\hline & \multirow{2}{*}{ For vertical loads } & \multicolumn{2}{|c|}{ For seismic actions } \\
\hline & & Ductile elements & Brittle elements \\
\hline & $f_{c d}(M p a)$ & $f_{c d}(M p a)$ & $f_{c d}(M p a)$ \\
\hline Columns on the ground floor & 9.00 & 15.87 & 10.58 \\
\hline Columns on the 1 st floor & 9.00 & 15.87 & 10.58 \\
\hline Columns on the 2 nd floor & 6.97 & 12.30 & 8.20 \\
\hline Columns on the 3 rd floor & 6.97 & 12.30 & 8.20 \\
\hline Steel bars & 342.03 & 393.33 & 342.03 \\
\hline
\end{tabular}

In Table 2, there are the strength values used in the safety assessment for vertical loads and seismic actions respectively for ductile and brittle elements.

\section{Structural performance of the existing building}

The numerical modelling (Figure 4) was carried out by using a finite element approach, implementing proper spatial models of the building structure within the solver SAP2000 Advanced 14.2.2 (2010) in order to perform the preliminary assessment, the modal analysis and the specific investigation of the non-linear behaviour.

Figure 4 3D numerical model

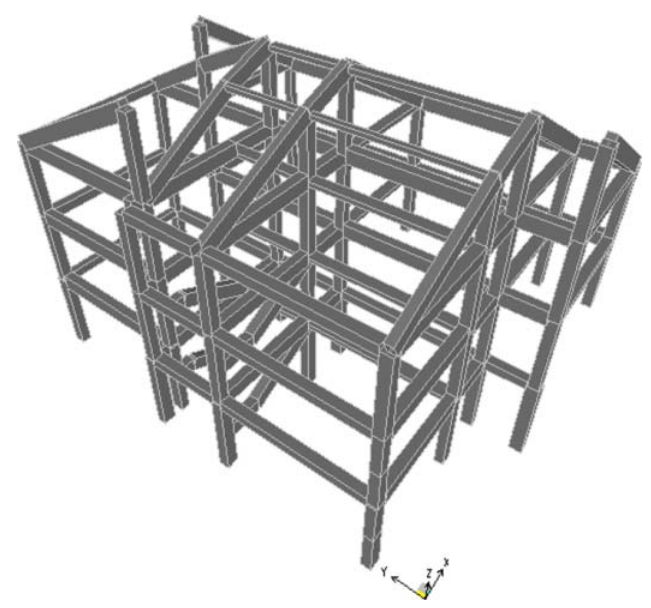

For the strongly irregular geometrical shape and its importance (the building is a school) in the numerical model the infilled frames were not included because they usually are not useful to correct structural deficiencies but often increase the irregularity.

In order to assess the dynamic behaviour of the building, a modal analysis was performed by implementing an elastic model and assuming the hypothesis of rigid floors. The fundamental periods $T(s)$ and effective modal masses $M_{X}(\%), M_{Y}(\%)$ corresponding to the first three vibration modes are collected in Table 3. 
Table 3 Modal analysis results

\begin{tabular}{llcc}
\hline Mode & $T(s)$ & $M_{X}(\%)$ & $M_{Y}(\%)$ \\
\hline 1 & 0.40 & 38.31 & 13.80 \\
2 & 0.36 & 39.77 & 46.91 \\
3 & 0.32 & 12.80 & 31.55 \\
\hline
\end{tabular}

The results show clearly the effects of the structural irregularity. In fact, in $X$, direction the first modal shape is translational but the mass which is employed is only slightly higher than $38 \%$ while for the other translational modal shape, mass is just equal to $46 \%$. In both shapes modal, translation movement is accompanied by a rotational motion due to irregularities in elevation deriving from foundations which are on two levels. Also the pushing load transmitted by the coverage (characterised by an articulated and non-uniform sloping) increases the effects due to irregularity in height. Therefore, on the basis of results the intervention of seismic retrofitting planned is mainly aimed at reducing the irregularity of the building and its effects on the global dynamic behaviour.

\subsection{Analysis for vertical loads}

The Italian technical rules indicate the conditions in which safety verifications must be carried out. If under non-seismic loads the safety verification is negative, urgent measures aimed at restoring the required performance level must be immediately adopted; otherwise the structure should be dismissed.

Compared to vertical loads, safety assessment according to only ultimate limit state (SLU) was carried out taking into account the fundamental combination which contains partial coefficients both permanent and variable loads.

Table 4 provides a summary of the results related to safety assessment for the case study. For every structural typology there is indicated the number of elements that are not verified and their percentage than global number.

Table 4 Results of analysis for vertical loads

\begin{tabular}{lccc}
\hline & $\begin{array}{c}\text { Number of } \\
\text { elements not } \\
\text { verified }\end{array}$ & $\begin{array}{c}\text { Number of } \\
\text { elements verified }\end{array}$ & $\begin{array}{c}\text { Percentage of } \\
\text { elements not } \\
\text { verified }\end{array}$ \\
\hline Foundation & - & 19 & $17.4 \%$ \\
Columns on the ground floor & - & 17 & - \\
Columns on the 1st floor & - & 17 & - \\
Columns on the 2nd floor & - & 8 & - \\
Columns on the 3rd floor & - & 17 & - \\
Beams on the 1st floor & - & 24 & - \\
Beams on the 2nd floor & - & 24 & $5.6 \%$ \\
Beams on the 3rd floor & 1 & 17 & - \\
Coverage beams & & - & 17 \\
\hline
\end{tabular}


Overall, the percentage of columns and beams that do not satisfy the verification is very low. Therefore, the daily use of the school was allowed until the execution of the seismic retrofitting. Of course, the few structural deficiencies found have been properly eliminated with specific local interventions.

\subsection{Non-linear static analysis}

In the non-linear field, the safety levels were evaluated compared to the limit state of damage severe [SLV in NTC (2008) and DS in EC8] combining loads according to the following relation:

$$
G_{1}+G_{2}+E \sum_{j} \psi_{2 j} Q_{k j}
$$

where

$G_{1}$ and $G_{2}$ structural and not structural permanent load

E seismic action

$\psi_{2} \quad$ combination coefficient

$Q_{k} \quad$ characteristic value of variable action.

The elastic design spectrum was chosen according to the Italian standards, as a function of the parameters $a_{g}, F_{0}$ and $T_{C}^{*}$ (respectively: design ground acceleration on type A ground; maximum amplification factor for the horizontal acceleration; corner period at the upper limit of the constant acceleration region of the elastic spectrum) determined on the base of the geographic location of the building. In addition, the other main parameters for assessing the elastic spectral shape are: class of use III $\left(C_{U}=1.5\right)$, the nominal life $V_{N}=50$ years (consequently the reference life given by product between $C_{U}$ and $V_{N}$ is equal to 75 years); ground type $B$; topographic factor $T_{2}$.

The non-linear behaviour of columns and beams was described according to a lumped plasticity approach. According to this, the post-elastic behaviour is modelled by introducing plastic hinges in which all non-linearity are located at the ends of the elastic beams representing the structural elements. The non-linearity of the plastic hinge is defined by $M-\phi$ or $M-\theta$ relationship including as a parameter the shear span $L_{V}$, which varies during the incremental pushover loading. In this research work the non-linear constitutive law contained within the FEMA-356 (Federal Emergency Management Agency, 2000) was adopted. The rotations corresponding to the yielding moment $\theta y$ and to the ultimate moment $\theta u$ were evaluated according to the specifications of the Italian seismic code (see Sections C8.7.2.5 and C8A.6.) which are in agreement with the European standards.

Along the main directions of the building, two different lateral distributions of incremental loads were applied (the first proportional to mass, the second to the fundamental modal shape). The pushover curves in the positive directions $(+X$ and $+Y)$ are shown in Figure 5, considering all elements with a ductile behaviour and consequently a flexural collapse mechanism. This assumption aims to assess the structural capacity in terms of resistance assuming that the seismic retrofitting provides inside the restore of brittle elements. The nearly lack of the transversal reinforcement in the column-beam joints does not affects the capacity curves because the brittle collapse 
of the joint was not considered. Both projects involve corrective measures on the unconfined joints (as FRP) that allow to neglect the brittle behaviour of column-beam joints.

Figure 5 Capacity curve of the existing building before the seismic retrofitting interventions (see online version for colours)

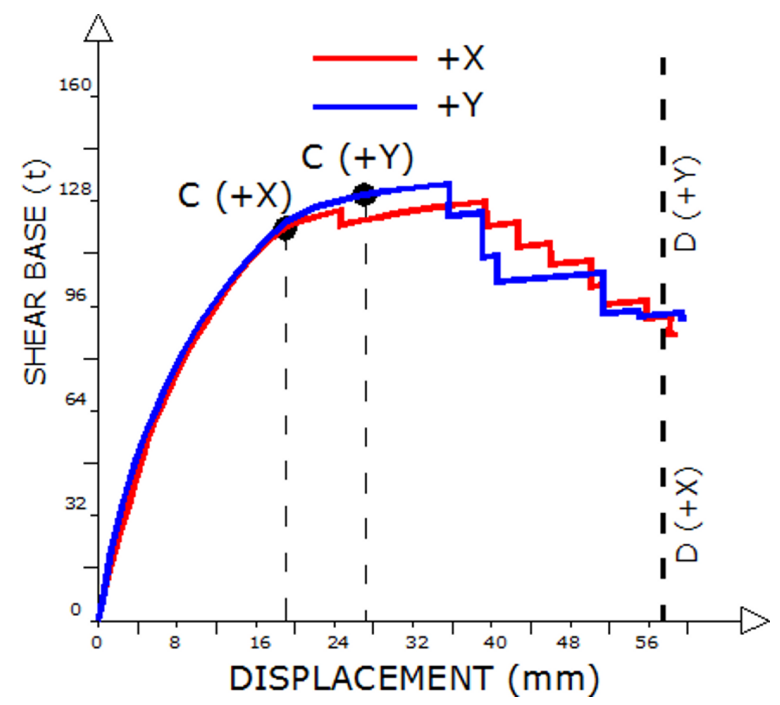

Table 5 reported the structural capacity (C) and seismic demand (D) evaluated according to the indications of Italian technical rules that are in line with N2 method. The presence of structural deficiency affects on the numerical evaluation in both directions and especially increases the flexural collapses occurring before the displacement demand. The decrease of resistance detected on both curves is the consequence to the achievement of the ultimate rotation in the end sections of the columns (mainly those located in the ground and first floor). This leads to increase the resistance of columns in favour of a greater capacity in terms of structural response.

Table 5 Capacity and demand for existing building before the seismic retrofitting interventions

\begin{tabular}{lcc}
\hline & $+X$ & $+Y$ \\
\hline $\mathrm{D}(\mathrm{mm})$ & 47.9 & 47.6 \\
$\mathrm{C}(\mathrm{mm})$ & 16.2 & 22.7 \\
$\mathrm{D} / \mathrm{C}<1$ & $2.95-\mathrm{NO}$ & $2.09-\mathrm{NO}$ \\
\hline
\end{tabular}

It should be noted that, the effective modal masses are less than $75 \%$ (see Table 3 ). Consequently, in accordance with the technical standards, the non-linear static analysis should not be used. Although for the present study, the pushover analysis was used because the seismic retrofitting is primarily designed to reduce the irregularity. Therefore, assessments of the structural performance, achieved after interventions can be considered more reliable than results concerning the current irregular conditions. 


\section{Proposals of seismic retrofitting}

Hereinafter will be presented two different seismic retrofitting interventions. The first is an intervention of the traditional type while the second consists in the use of techniques dissipative. The safety levels achieved since the adoption of these techniques will be compared with performance of the building found before the intervention (in the geometrical configuration hereinafter referred to as bare).

It should be noted that both interventions are completed by inserting strengthening with FRP (in carbon quadric-axial fabric) in the ends of vertical elements to increase the shear strength and ductility. The vertical elements affected by bandage with FRP are those located the first and second floors that were not reinforced. Instead, the beams were reinforced because they have sufficiently ductile behaviour under seismic actions.

\subsection{Intervention with sectional increase of columns}

The seismic verification concerning the current configuration (i.e., for the bare structure), showed a significant structural deficiency. The strain capacity at ultimate conditions is roughly equivalent to the displacement demand for SLV. The capacity is anticipated by several flexural collapses because the building has low stiffness and resistance. For this remarks, the first proposal has as main purpose the sectional increase of the vertical elements (hereinafter: 'reinforced columns') that are distributed along perimeter of the building. The solution allows to reduce irregularities highlighted in the behaviour dynamic of the bare configuration (Figure 6).

Figure 6 Intervention with sectional increase of vertical elements (see online version for colours)

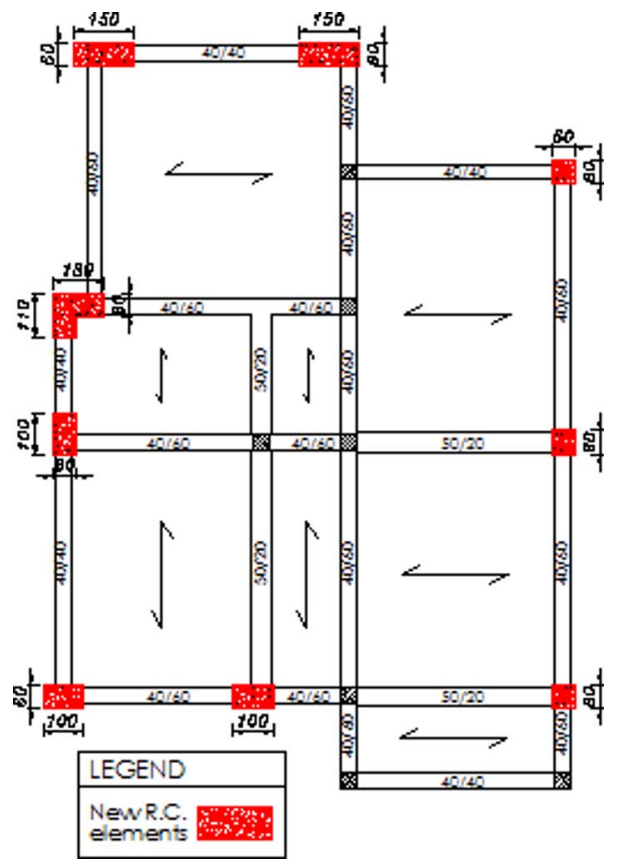


Table 6 collects the dynamic parameters of the numerical model with reinforced columns. Dynamic analysis shows (as was expected) the reduction of the period because the stiffness increases for the modification of the cross sectional of the columns.

Table 6 Modal analysis results after reinforced columns

\begin{tabular}{lccc}
\hline Mode & $T(s)$ & $M_{X}(\%)$ & $M_{Y}(\%)$ \\
\hline 1 & 0.23 & 0.24 & 87.12 \\
2 & 0.20 & 78.24 & 0.10 \\
3 & 0.16 & 7.02 & 0.31 \\
\hline
\end{tabular}

The first two vibration modes are perfectly translational because. They have percentage of mass involved in one of the two main directions and in value greater than $75 \%$. The third modal shape is rotational and mass involved along the principal directions are very small in percentage terms. Comparing the values with those obtained for bare configuration (Table 3) it is evident the significant modification of the dynamic behaviour, which is now similar to a regular structural configuration.

Increasing the cross-sections of the columns along the perimeter, the strain capacity (C) is greater than the demand (D) in both directions. The reinforced columns produce an increase in the strength and ductility of the building. An overall summary of the results are in Figure 7 and Table 7.

Figure 7 Capacity curves of the building with reinforced columns (see online version for colours)

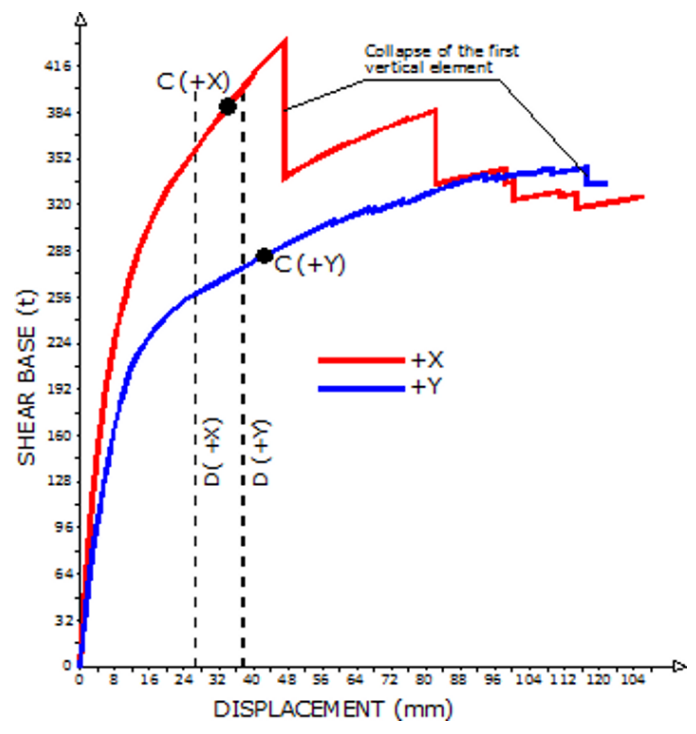

Table 7 Capacity and demand for existing building after the reinforced columns

\begin{tabular}{lcc}
\hline & $+X$ & $+Y$ \\
\hline $\mathrm{D}(\mathrm{mm})$ & 21.3 & 29.7 \\
$\mathrm{C}(\mathrm{mm})$ & 27.0 & 34.5 \\
$\mathrm{D} / \mathrm{C}<1$ & $0.78-$ YES & $0.86-$ YES \\
\hline
\end{tabular}




\subsection{Intervention with dissipative system}

An alternative technique for the seismic retrofitting has the aim to increase the energy dissipative of the structure simultaneously to the increase of stiffness and strength. This objective can be achieved using the hysteretical dampers - hereinafter 'dissipative systems'.

Figure 8 Position in plan and some pictures of dissipative systems (see online version for colours)

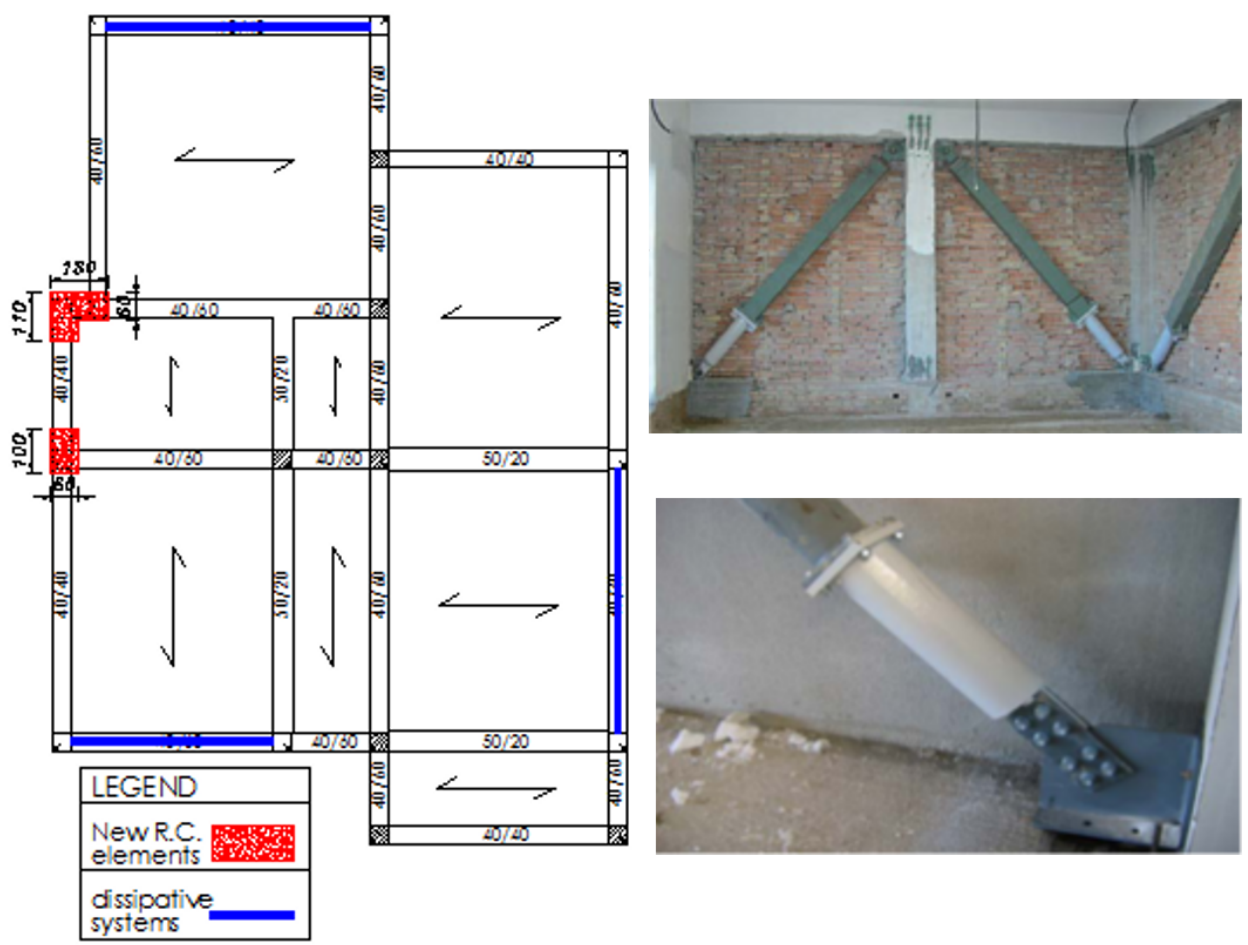

For the building in question the choice about dissipative systems, is due to the need to reduce the effects related to the irregularity. Number and position of the dissipative systems depend on openings and transit zones. Therefore, systems along the perimeter and for the whole height of the structure were predicted (Figure $8-$ left). This position allows to increase the rotational stiffness and consequently the rigid translation of the building. Near the stairs, it is difficult to include the dissipative systems; therefore, the columns were reinforced using the first intervention type. The devices proposed in this case study are called buckling restrained axial dampers (BRAD) and by steel element are made. In order to dissipate energy, they have high-ductility and can reach the yield strength, both in traction and in compression. (Figure 8 - right).

Table 8 shows the mechanical features of the BRAD devices used, such as yield strength $\left(F_{y}\right)$, force corresponding to maximum displacement $\left(F_{\max }\right)$, maximum displacement $\left(S_{\max }\right)$ and elastic stiffness $(K)$. 
Table 8 Main mechanical features of the BRAD devices

\begin{tabular}{lccccc}
\hline \multirow{2}{*}{$B R A D$ (size) } & Location & $F_{y}$ & $F_{\max }$ & $S_{\max }$ & $\mathrm{K}$ \\
\cline { 3 - 6 } & & $k N$ & $k N$ & $m m$ & $\mathrm{kN} / \mathrm{mm}$ \\
\hline $46 / 30$ & Ground floor in X dir. & 350 & 410 & \pm 15 & 385 \\
$39 / 30$ & 1st and 2nd floor in X dir. & 300 & 350 & \pm 15 & 305 \\
$41 / 40$ & in Y dir. & 300 & 360 & \pm 20 & 250 \\
\hline
\end{tabular}

The adoption of the BRAD systems having different stiffness has allowed to calibrate the intervention so as to reduce the eccentricity between mass and stiffness centres that causes the irregularity. This choice reduces the period $\mathrm{T}(\mathrm{s})$ similarly to the previous solution while the percentage of mass involved increases in $X$ direction because the modal shape is only translational (without rotational effects) - Table 9 .

Table 9 Modal analysis results after intervention with dissipative system

\begin{tabular}{lccc}
\hline Mode & $T(s)$ & $M_{X}(\%)$ & $M_{Y}(\%)$ \\
\hline 1 & 0.23 & 0.57 & 85.23 \\
2 & 0.20 & 90.81 & 0.75 \\
3 & 0.15 & 0.34 & 5.45 \\
\hline
\end{tabular}

Also for dissipative systems, the non-linear static analysis was carried out. Compared to traditional intervention, the analysis provides the structural collapse in correspondence with the failure of BRAD devices. When the resistance provided by dissipative systems ends only the bare structure remains to oppose the seismic action.

Figure 9 Capacity curves of the building with dissipative systems (see online version for colours)

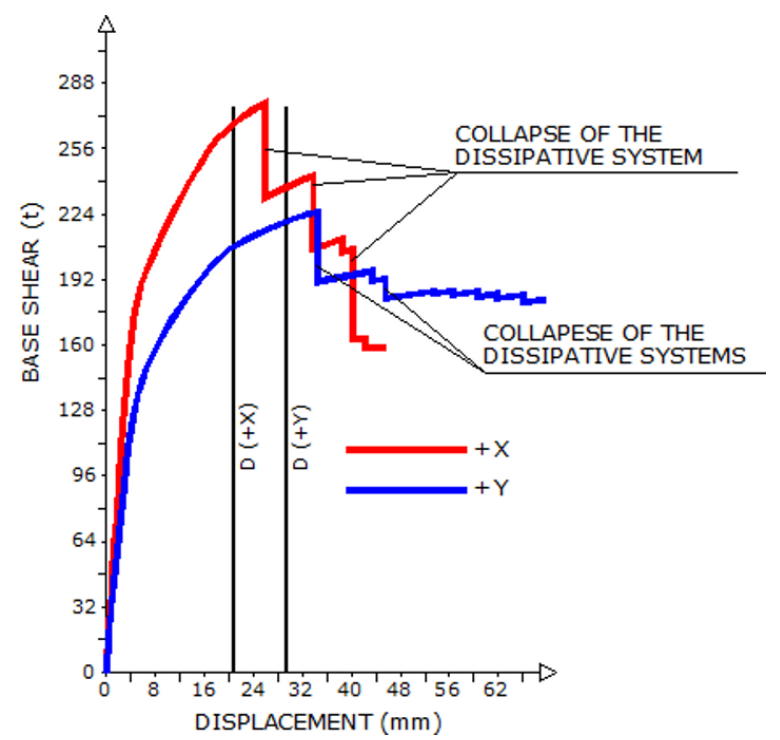


Figure 9 shows the push-over curves along the two main directions of the building $(+X$ and $+Y)$. The substantial decay of resistance, characterising these curves, is in correspondence of displacements where the collapse of the dissipative systems (BRAD devices) occurs.

The assessment of the geometrical and mechanical features of BRAD devices was carried out so that they can reach (during their service life) displacements lower than the design values. It is evident, therefore, that the structural seismic demand should precede the displacement at the collapse of the first BRAD devices. For the case of study, this aim was reached. For DS, the structural capacity (in terms of displacement) is greater than seismic demand. The base shear is lower of $18 \%$ and $24 \%$, respectively, in the $X$ and $Y$ direction than the solution with reinforced columns (Table 10). Also safety factor, in both directions, is roughly similar to the value obtained with the first proposal of.

Table 10 Capacity and demand for existing building after the intervention with dissipative system

\begin{tabular}{lcc}
\hline & $+X$ & $+Y$ \\
\hline $\mathrm{D}(\mathrm{mm})$ & 21.3 & 29.7 \\
$\mathrm{C}(\mathrm{mm})$ & 27.0 & 34.5 \\
$\mathrm{D} / \mathrm{C}<1$ & $0.78-\mathrm{YES}$ & $0.86-\mathrm{YES}$ \\
\hline
\end{tabular}

\section{Some remarks}

With reference to the solutions outlined above, in Figure 10 are shown the non-linear responses of the structure. The curves are plotted until the first ten structural elements reach the flexural collapse (meaning by 'collapse' the achievement of the ultimate rotation in the end sections of the beam or column). The comparison with the behaviour of the 'bare' frame reveals some interesting considerations relating to the two interventions proposed.

A first important consideration concerns the stiffness of the structure after the interventions. With the aim to obtain fundamental periods similar to those obtained by increasing the cross sections of the vertical elements, the dissipative systems were sized. If the periods of vibration are similar, the comparison between the two seismic retrofitting solutions it makes sense.

Reinforcement of the columns induces a strong increase of the structural strength by $340 \%$ and $250 \%$ respectively, in $X$ and $Y$ direction. The overall capacity has greatly increased. The first ten flexural collapses are in correspondence with the maximum displacement of about $140 \mathrm{~mm}$, compared with only $60 \mathrm{~mm}$ and $58 \mathrm{~mm}$ respectively for bare structure and solution with dissipative systems.

For the building with reinforced columns, the high decrease in strength shown at first collapse is higher than displacement demand. In the interval between the collapse of the first columns and the demand (equal to $22 \mathrm{~mm}$ ) there is an increase of resistance by about $80 \mathrm{t}$. 
Figure 10 Capacity curves of the building after the first ten flexural collapse: comparison between proposals for seismic retrofitting (see online version for colours)

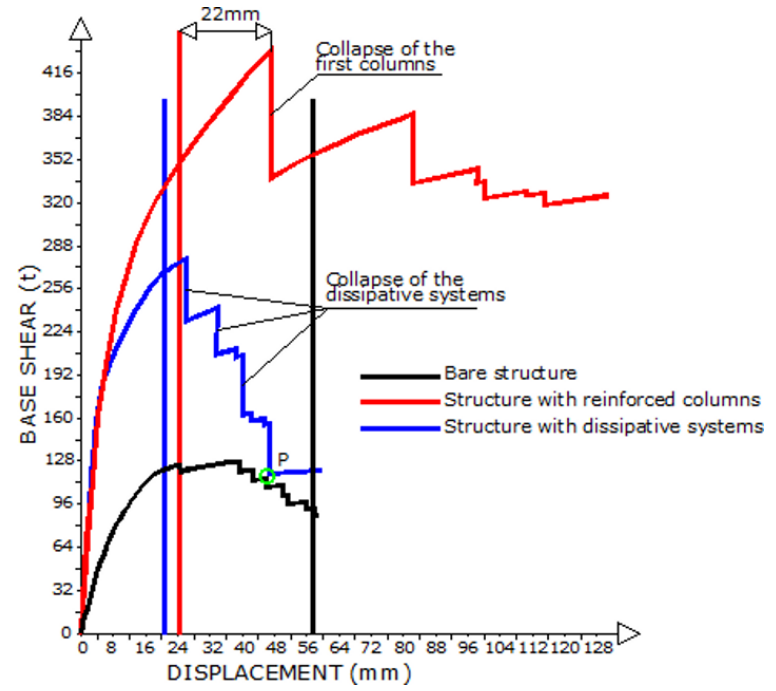

On the other hand, the behaviour shown by the structure with dissipative systems is quite different. The increase of the base shear and strain capacity induced by the energy dissipation ends when all the BRAD devices go out of service for the attainment of the maximum displacement. From this stage onwards, the non-linear response is without dissipative systems and the pushover curve becomes equivalent to those of the bare frame. The point $P$ marked in the figure indicates the displacement value where there is actually this change.

This confirms the analogy between frames with dissipative systems and the infilled frames whose non-linear response is the point of union with the response of the bare structure once the contribution in resistance of dampers is voided (Uva et al., 2012a, 2012b; Fiore et al., 2012; Fajfar and Dolsek, 2004; Chrysostomou and Asteris, 2012). The observed behaviour is very advantageous, as it reached the top ten collapses; there are no collapses in primary elements while attaining the maximum displacement of the bare frame.

\section{Conclusions}

The paper collects the seismic analysis of a reinforced concrete school building located in a small town in the Southern Italy. After detailed investigations, a high security deficit to seismic actions was revealed. On the basis on the results, two different solutions have been suggested in order to seismically retrofit the building. The first involves an increase of the cross section of the columns; the second involves the use of dissipative systems.

Among the possible solutions for seismic retrofitting, the possibility of a base isolation due to strong irregularities in elevation was discarded. Therefore, both solutions provide for the elimination of the brittle mechanisms, such as those of the unconfined beam-column joints, the regularisation of the dynamic behaviour of the structure and the increase of the global stiffness. By comparing the two proposals, we can see that 
the reinforcement of the vertical elements leads to an increase of the resistance (i.e., global-base shear). The dissipative systems, instead, allow to obtain the same displacements but a lower increase in resistance, which is certainly positive for the verification of the foundation.

It is important to note that the use of dissipative devices essentially allows to have structural fuses for seismic actions. For high values of demand, they break to preserve the main elements (columns and beams) and therefore allow to establish a sort of structural hierarchy, as provided for new buildings by the most recent technical rules.

At the end, limited to the present case study, we can say that the seismic retrofitting with dissipative systems allows us to achieve a structural response in line with the performance requirements of the technical regulations in force (hierarchy of the resistances, ductility, etc.). The building does not present many deficiencies compared to the vertical loads and therefore, for the need to regularise the dynamical behaviour and improve the overall seismic capacity, the dissipative devices appear to be between the two solutions, the best one.

It should be noted that this statement can not be generally extended to any building. If there are deficiencies in relation to vertical loads is necessary to increase the resistance of the structural elements (especially the columns). Consequently, the first intervention (which provides the reinforcement of the columns) is certainly required. Obviously, the regularity, age, material properties and degradation of the generic structure, play a binding role in the choice of the seismic retrofitting intervention.

\section{References}

American Concrete Institute (2003) Guide for Obtaining Cores and Interpreting Compressive Strength Results, ACI 214.4R-03, Reported by ACI Commitee 214. Detroit, Michigan.

Celarec, D. and Dolsek, M. (2013) 'The impact of modelling uncertainties on the seismic performance assessment of reinforced concrete frame buildings', Engineering Structures, July, Vol. 52, pp.340-354.

Celarec, D., Ricci, P. and Dolsek, M. (2012) 'The sensitivity of seismic response parameters of the uncertain modeling variables of masonry-infilled reinforced concrete frames', Engineering Structures, February, Vol. 35, pp.165-177.

CEN (2005a) Eurocode 2: Design of Concrete Structures - Part 1-1: General Rules and Rules of Buildings, European Prestandard, EN 1992-1-1, Brussels, Belgium.

CEN (2005b) Eurocode 8: Design Provisions for Earthquake Resistance of Structures - Part 3: Assessment and Retrofitting of Buildings, European Committee for Standardisation EN1998-3, Brussels, Belgium.

Chrysostomou, C.Z. and Asteris, P.G. (2012) 'On the in-plane properties and capacities of infilled frames', Engineering Structures, August, Vol. 41, pp.385-402.

Circolare Ministeriale del 2 febbraio n. 617 (2009) Approvata dal Consiglio Superiore dei Lavori Pubblici, Istruzioni per l'applicazione delle 'Nuove norme tecniche per le costruzioni' di cui al Decreto Ministeriale 14 gennaio 2008 - 2009 (in Italian).

Collepardi, M. (2010) The New Concrete, Edizioni Tintoretto, Villarba, Italy.

NTC (2008) 'DM 14/01/2008. Norme Tecniche per le Costruzioni', Gazzetta Ufficiale n.29, Istituto Poligrafico e Zecca dello Stato, Roma, (in Italian), Italy.

Fajfar, P. and Dolšek, M. (2004) 'Inelastic spectra for infilled reinforced concrete frames', Earthquake Engineering and Structural Dynamics, Vol. 33, No. 15, pp.1395-1416. 
FEMA-274 (1997) NEHRP Commentary on the Guidelines for the Seismic Rehabilitation of Buildings, FEMA 274, Washington, DC.

Federal Emergency Management Agency (2000) Prestandard and Commentary for the Seismic Rehabilitation of Buildings, FEMA-356, American Society of Civil Engineers, Washington, DC.

Fiore, A., Porco, F., Raffaele, D. and Uva, G. (2012) 'About the influence of the infill panels over the collapse mechanisms actived under pushover analyses: two case studies', Soil Dynamics and Earthquake Engineering, August, Vol. 39, pp.11-22.

Fiore, A., Porco, F., Uva, G. and Mezzina, M. (2013) 'On the dispersion of data collected by in situ diagnostic of the existing concrete', Construction and Building Materials, October, Vol. 47, pp.208-217.

Malhotra, V.M. (1974) 'Contract strength requirements - cores versus in situ evaluation', $A C I$ Journal Proceedings, Vol. 74, No. 4, pp.163-72.

Masi, A. (2005) 'La stima del calcestruzzo in situ mediante prove distruttive e non distruttive', $I l$ giornale delle prove non distruttive, 1-2005, pp.1-9 (in Italian).

Mazza, F. and Vulcano, A. (2009) 'Nonlinear response of RC framed buildings with isolation and supplemental damping at the base subjected to near-fault earthquakes', Journal of Earthquake Engineering, Vol. 13, No. 5, pp.690-715.

Mazza, F., Vulcano, A. and Mazza, M. (2012) 'Nonlinear dynamic response of RC buildings with different base-isolation systems subjected to horizontal and vertical components of near-fault ground motions', The Open Construction \& Building Technology Journal, Vol.6, pp.373-383.

Mezzina, M., Monti, G., Uva, G., Marano, G., Raffaele, D., Greco, R. et al. (2009) 'Prime considerazioni sul comportamento delle costruzioni nel terremoto de L'Aquila', Ingegneria Sismica, ISSN 0383-1420, Pàtron Editore, Granarolo dell'Emilia (Bo), Italy, n. 2/2009, pp.7-25.

Mikulic, D., Pause, Z. and Ukraincik, V. (1992) 'Determination of concrete quality in a structure by combination of destructive and non-destructive methods', Material \& Structures, Vol. 25, No. 146, pp.65-69.

Ponzo, F.C., Di Cesare, A., Nigro, D., Vulcano, A., Mazza, F., Dolce, M. and Moroni, C. (2012) 'JET-PACS project: dynamic experimental tests and numerical results obtained for a steel frame equipped with hysteretic damped chevron braces', Journal of Earthquake Engineering, Vol. 16, No. 5, pp.662-685.

Porco, F., Fiore, A., Uva, G. and Raffaele, D. (2014) 'The influence of infilled panels in retrofitting interventions of existing reinforced concrete buildings: a case study', Structure \& Infrastructure Engineering, DOI:10.1080/15732479.2013.862726.

Qasrawi, H.Y. (2000) 'Concrete strength by combined nondestructive methods simply and reliably predicted', Cement \& Concrete Research, Vol. 30, No. 5, pp.739-746.

Raffaele, D., Mezzina, M. and Tosto, A. (2013) 'Overview on the regional scale analysis of school buildings in Puglia (Italy)', in Papadrakakis, M., Papadopoulos, V. and Plevris, V. (Eds.): COMPDYN 2013 4th ECCOMAS Thematic Conference on Computational Methods in Structural Dynamics and Earthquake Engineering, Kos Island, Greece.

Rossetto, T. and Peiris, N. (2009) 'Observations of damage due to the Kashmir earthquake of October 8, 2005 and study of current seismic provisions for buildings in Pakistan', Bulletin of Earthquake Engineering, Vol. 7, No. 3, pp.681-699.

SAP2000 Advanced 14.2.2 (2010) Structural Analysis Program - Manual, Computer and Structures, Inc, Berkeley, California, USA.

Uva, G., Porco, F. and Fiore, A. (2012a) 'Appraisal of masonry infill walls effect in the seismic response of RC framed buildings: a case study', Engineering Structures, Vol. 34, No. 1, pp.514-526. 
Uva, G., Porco, F., Raffaele, D. and Fiore, A. (2012b) 'On the role of equivalent strut models in the seismic assessment of infilled RC buildings', Engineering Structures, September, Vol. 42, pp.83-94.

Uva, G., Porco, F., Fiore, A. and Mezzina, M. (2013) 'Proposal of a methodology of in-situ concrete tests and improving the estimate of the compressive strength', Construction and Building Materials, Vol. 38, No. 1, pp.72-83. 